DOI: 10.12731/2070-7568-2017-2-114-131

УДК 332.012:332.025:333.1

\title{
ГОСУДАРСТВЕННО-ЧАСТНОЕ ПАРТНЕРСТВО В СЕВЕРНЫХ РЕГИОНАХ РОССИИ
}

\section{Гасникова А.А., Чапаргина А.Н.}

Рассмотрены основные вопросы организации и нормативно-правового обеспечения государственно-частного партнерства (ГЧП). Проанализированы рейтинговые оченки северных регионов России по уровню развития государственно-частного партнерства в 20132016 г2. Исследована структура проектов ГЧП на региональном уровне по объему частных инвестищий, уровню и видам реализации. Концептуально обоснованы предложения по дальнейшему развитию ГЧП в регионах. Обоснована необходимость развития единой системы контроля и мониторинга проектов ГЧП, повыпения инвестиционной привлекательности региона в иелом, использования дополнительных финансовых инструментов для финансирования проектов, повышения информированности о проектах ГЧП, создание площадок для открытой дискуссии представителей власти и бизнеса.

Цель: выявить особенности развития ГЧП в северных регионах России.

Методы или методология проведения работы: анализ и синтез, сравнение, сочетание индуктивного и дедуктивного методов, статистические и математические методы, а также комплексный подход.

Результаты: проанализировано правовое обеспечение ГЧП; представлен анализ рейтинговых оценок ГЧП; выделены особенности его развития в северных регионах; даны рекомендащии по активизации ГЧП на региональном уровне.

Область применения результатов: полученные результаты могут быть использованы для решения методологических и практических задач по совершенствованию развития ГЧП в России с учетом региональных особенностей. 
Ключевые слова: государство и бизнес; согласование интересов; государственно-частное партнерство; рейтинг; региональное развитие; северные регионы.

\section{PUBLIC-PRIVATE PARTNERSHIPS IN THE NORTHERN REGIONS OF RUSSIA}

\section{Gasnikova A.A., Chapargina A.N.}

The main issues of the organization and regulatory support of public-private partnerships (PPP) are examined. Ratings of the Northern regions of Russia on the PPP development level in 2013-2016 are analysed. The structure of PPP projects on the volume of private investments, the level and types of realization is shown. Conceptual proposals on further development of the PPP at the regional level are substantiated. The necessity of development of the integrated system of control and monitoring of PPP projects, increasing of investment appeal of the region, using of additional financial instruments for financing of projects, increasing of informing about the PPP projects, and create grounds for an open discussion of public and business agents are proved.

Purpose: revealing the features of PPP development in the Russian northern regions.

Methodology: analysis and synthesis, comparison, combination of inductive and deductive methods, statistical and mathematical methods, and systematic approach.

Results: the regulatory support of the PPP mechanism was analyzed; rating of PPPs is presented; features of its development in the northern regions are described; recommendations about the activation of PPP at the regional level are given.

Practical implications: the presented solutions and recommendations are intended for solving methodological and practical problems of improving the PPP development in Russia, taking into account regional features.

Keywords: state and business; alignment of interests; public-private partnerships; rating; regional development; Northern regions. 
Для государства очевидна важная роль социального благополучия страны и отдельных субъектов Федерации. Обеспечение социального благополучия невозможно без развития производства и сферы услуг, то есть без экономического развития. Это подтверждается анализом главных целей стратегий социально-экономического развития некоторых субъектов Федерации [12]. Одним из механизмов достижения поставленных целей социально-экономического развития является государственно-частное партнерство (ГЧП). Оно позволит привлекать частные инвестиции в экономику регионов, обеспечить эффективное использование имущества, находящегося в собственности региональных органов власти, повышать качество товаров и услуг, предоставляемых потребителям.

Сегодня не существует единого международно-признанного определения ГЧП [20]. Не определено оно и на уровне Европейского Союза [19]. В то же время в зарубежной и отечественной литературе можно найти множество трактовок этого понятия $[1,3,5,8,9,10$, $17,20,21]$. Государственно-частное партнерство рассматривается как совокупность форм взаимодействия государства и бизнеса для решения общественно значимых задач на взаимовыгодных условиях; как правовой механизм согласования интересов и обеспечения взаимодействия государства и бизнеса; как механизм, посредством которого возможна реализация приоритетных инвестиционных проектов. Для целей нормативно-правового регулирования в России понятие ГЧП закреплено в законе №224-Ф3 «О государственно-частном партнерстве, муниципально-частном партнерстве в Российской Федерации и внесении изменений в отдельные законодательные акты Российской Федерации» [15]. В данном законе выделены основные элементы концептуальной модели ГЧП, подробно описанные в работе [7]: публичный партнер, частный партнер, финансирующая организация, программы социально-экономического развития.

ГЧП - это не просто сложение ресурсов и распределение рисков. В первую очередь, оно требует достижения баланса интересов участников - власти и бизнеса. Объединяясь в форме ГЧП, государство в лице органов власти и частный партнер преследуют 
разные цели. Частный партнер стремится к росту своего бизнеса, максимизации прибыли и эффективному использованию ресурсов. Государство как представитель общественных интересов стремится обеспечить, прежде всего, устойчивое социально-экономическое развитие. Кроме этого, у государства, особенно на уровне субъекта Федерации, может не хватать средств на реализацию социально значимых проектов, а частные предприятия могут быть не заинтересованы в них вследствие отсутствия или недостаточно высокой прибыли. В качестве примера можно привести ситуацию с топливоснабжением Хатангского сельского поселения в Красноярском крае [14]. Топливо для нужд поселения завозится из других районов несмотря на значительные запасы каменных углей расположенного в 40 км от Хатанги Котуйского угольного месторождения. Региональный и местный бюджеты не могут выступить инвестором в разработку месторождения из-за ограниченности финансовых возможностей, а для частного инвестора данный проект не интересен, поскольку связанная с его реализацией экономия бюджетных средств на «северный завоз» не пойдет на формирование его прибыли. Как способ решить сложившуюся проблему рассматривается именно создание действенного механизма ГЧП.

Для эффективной реализации проектов на основе ГЧП требуется его хорошо проработанное нормативно-правовое обеспечение. На начальной стадии развития ГЧП его управлением на региональном уровне занимались различные структурные подразделения исполнительных органов власти, причем их действия часто были не скоординированы [11]. В 2000-х гг. на региональном уровне начали появляться законы о ГЧП. По данным на 2015 г. в России действовал 71 закон субъекта РФ в сфере ГЧП [13]. К этому времени уже была очевидна необходимость принятия федерального закона, регулирующего применение рассматриваемого механизма взаимодействия государства и частных предприятий.

13 июля 2015 г. был принят, и 1 января 2016 г. вступил в силу федеральный закон № 224-Ф3, регулирующий отношения государственно-частного партнерства. В его развитие был принят ряд 
подзаконных актов (приказов Минэкономразвития РФ, постановлений Правительства РФ), регламентирующих порядок организации предварительных переговоров, проведение оценки эффективности реализации проектов, предварительный отбор частного партнера и другие вопросы. Важное место среди них занимает федеральный закон от 21 июля 2005 г. № 115-Ф3 «О концессионных соглашениях», поскольку большинство проектов ГЧП реализуются именно в форме таких соглашений.

После принятия федерального закона № 224-Ф3 перед субъектами Федерации встала задача привести свое региональное законодательство в соответствие с федеральным. Часть из них признали принятые ранее региональные законы о ГЧП утратившими силу с целью избежать дублирования федерального законодательства или противоречия ему (табл. 1).

Таблицуа 1.

Законы некоторых субъектов РФ о ГЧП, принятые до вступления в силу Федерального закона от 13 июля 2015 года № 224-Ф3

\begin{tabular}{|c|c|c|}
\hline $\begin{array}{c}\text { Субъект } \\
\text { Федерации }\end{array}$ & Закон субъекта Федерации о ГЧП & $\begin{array}{c}\text { Статус Закона на конец } \\
2016 \text { года }\end{array}$ \\
\hline $\begin{array}{l}\text { Республика } \\
\text { Карелия }\end{array}$ & $\begin{array}{l}\text { Закон от 05.12.2011 № 1568-ЗРК «Об } \\
\text { участии Республики Карелия в про- } \\
\text { ектах государственно-частного пар- } \\
\text { тнерства» }\end{array}$ & $\begin{array}{l}\text { Утратил силу (Закон } \\
\text { Республики Карелия от } \\
25 \text { июля } 2016 \text { года № } \\
2037-3 Р К)\end{array}$ \\
\hline $\begin{array}{l}\text { Республика } \\
\text { Коми }\end{array}$ & $\begin{array}{l}\text { Закон от } 19.06 .2014 \text { № 71-Р3 «О го- } \\
\text { сударственно-частном партнерстве в } \\
\text { Республике Коми» }\end{array}$ & $\begin{array}{l}\text { Утратил силу (Закон РК } \\
\text { от 01.03.2016 № 17-Р3) }\end{array}$ \\
\hline $\begin{array}{l}\text { Республика } \\
\text { Саха (Яку- } \\
\text { тия) }\end{array}$ & $\begin{array}{l}\text { Закон от } 02 \text { апреля } 2014 \text { года № } 1293- \\
3 \text { № } 141-\mathrm{V} \text { «Об участии Республики } \\
\text { Саха (Якутия) в инфраструктурных } \\
\text { проектах государственно-частного } \\
\text { партнерства» }\end{array}$ & $\begin{array}{l}\text { Утратил силу (Закон } \\
\text { Республики Саха (Яку- } \\
\text { тия) от 15.06.2016 1661-3 } \\
\text { № 871-V) }\end{array}$ \\
\hline $\begin{array}{l}\text { Республика } \\
\text { Тыва }\end{array}$ & $\begin{array}{l}\text { Закон от 02.11.2009 № } 1552 \text { ВХ-2 «Об } \\
\text { участии Республики Тыва в государ- } \\
\text { ственно-частных партнерствах» }\end{array}$ & Действующий \\
\hline $\begin{array}{l}\text { Камчатский } \\
\text { край }\end{array}$ & $\begin{array}{l}\text { Закон от 09.10.2012 № } 133 \text { «О госу- } \\
\text { дарственно-частном партнерстве в } \\
\text { Камчатском Крае» }\end{array}$ & $\begin{array}{l}\text { Утратил силу (Закон } \\
\text { Камчатского края от } \\
\text { 27.04.2016 № 779) }\end{array}$ \\
\hline
\end{tabular}


Окончание табл. 1.

\begin{tabular}{|c|c|c|}
\hline $\begin{array}{l}\text { Архангель- } \\
\text { ская область }\end{array}$ & $\begin{array}{l}\text { Областной закон от 30.09.2011 № } \\
\text { 332-24-О3 «Об участии Архангель- } \\
\text { ской области в проектах государ- } \\
\text { ственно-частного партнерства» }\end{array}$ & Действующий \\
\hline $\begin{array}{l}\text { Мурманская } \\
\text { область }\end{array}$ & $\begin{array}{l}\text { Закон от 27.12.2010 № 1311-01-3МО } \\
\text { «Об участии Мурманской области } \\
\text { в государственно-частных партнер- } \\
\text { ствах» }\end{array}$ & $\begin{array}{l}\text { Утратил силу (Закон } \\
\text { Мурманской областной } \\
\text { Думы от 10.05.2016 № } \\
\text { 1999-01-3МО) }\end{array}$ \\
\hline $\begin{array}{l}\text { Ненецкий } \\
\mathrm{AO}\end{array}$ & $\begin{array}{l}\text { Закон от } 19.12 .2011 \text { № 83-О3 «Об } \\
\text { участии Ненецкого АО в государ- } \\
\text { ственно-частном партнерстве» }\end{array}$ & Действующий \\
\hline $\begin{array}{l}\text { Ханты-Ман- } \\
\text { сийский АО }\end{array}$ & $\begin{array}{l}\text { Закон от 18.10.2010 № 155-оз «Об } \\
\text { участии Ханты-Мансийского АО - } \\
\text { Югры в государственно-частных } \\
\text { партнерствах» }\end{array}$ & $\begin{array}{l}\text { Утратил силу (Закон Хан- } \\
\text { ты-Мансийского авто- } \\
\text { номного округа - Югры } \\
\text { от 31.03.2016 № 29-о3) }\end{array}$ \\
\hline $\begin{array}{l}\text { Ямало-Не- } \\
\text { нецкий АО }\end{array}$ & $\begin{array}{l}\text { Закон от 01.03.2010 № 29-3АО «Об } \\
\text { участии Ямало-ненецкого АО в про- } \\
\text { ектах государственно-частного пар- } \\
\text { тнерства» }\end{array}$ & $\begin{array}{l}\text { Утратил силу (Закон } \\
\text { ЯНАО от } 24.06 .2016 \\
\text { № 62-3АО) }\end{array}$ \\
\hline
\end{tabular}

Источник: составлено авторами на основе: Электронный фонд правовой и нормативно-технической документации. URL: http://docs.cntd.ru

Таким образом, процесс формирования нормативно-правового обеспечения ГЧП в России начинался «снизу» - на уровне субъектов, которые, стремясь решить проблемы социально-экономического развития, искали пути построения эффективного взаимодействия региональной власти и бизнеса. Однако после принятия Ф3 № 224- этот процесс стал происходить «сверху», и развитие нормативно-правового обеспечения ГЧП приобрело системный характер.

Внимание к ГЧП как к механизму осуществления хозяйственной деятельности особенно велико в регионах Севера, где более высоки затраты на развитие социальной инфраструктуры и больше издержки производства ввиду холодного климата и тяжелых условий хозяйствования в целом. Кроме этого, в большинстве северных регионов основной объем прибыли (до 90\%) формируют крупные градообразующие предприятия, входящие в структуру холдингов. Управляющие компании холдингов зарегистрированы чаще всего 
вне региона и не заинтересованы в осуществлении вложений в региональное развитие. Соответственно основные финансовые потоки, заработанные на территории региона, выводятся из него [16].

Для оценки ситуации в северных регионах был использован Рейтинг развития регионов по уровню ГЧП, разработанный Центром развития государственно-частного партнерства [13]. При составлении рейтинга за 2013/2014 и 2014/2015 гг. учитывались следующие факторы: развитость институциональной среды; опыт реализации проектов ГЧП; инвестиционная привлекательность региона. При составлении рейтинга 2015/2016 гг. в методику были внесены изменения: фактор «Инвестиционная привлекательность» заменен фактором «Институциональная среда»; добавлен фактор «Нормативно-правовая база»; изменились максимально возможные значения баллов по каждому фактору. По мнению авторов, несмотря на внесенные изменения в методику расчета рейтинга, анализ его динамики представляется полезным и целесообразным, поскольку позволяет отследить основные тенденции развития ГЧП в регионах и сравнить их со среднероссийским уровнем (табл. 2). При этом следует иметь в виду не только изменение составляющих рейтинга, но и изменение веса этих составляющих в интегральной оценке. Так, с принятием федерального закона о ГЧП сильное изменение претерпела такая составляющая рейтинга, как институциональная среда. Этот фактор был разделен на два: собственно институциональная среда и нормативно-правовое обеспечение, отражающее изменения в нормативно-правовых актах субъектов РФ о ГЧП и приведение их в соответствие с нормами федерального законодательства.

Начиная с 2014 г. (а в 6 регионах - с 2013 г.) во всех северных регионах рейтинг уровня развития ГЧП показал отрицательную динамику, что соответствовало общероссийской тенденции. Возможно, это связано с исключением при расчете рейтинга фактора «инвестиционная привлекательность». Свою роль сыграло также замедление темпов роста российской экономики в целом и потеря интереса у потенциальных инвесторов к долгосрочным проектам на региональном и муниципальном уровне. 
Таблицуа 2.

Рейтинг северных регионов по уровню развития ГЧП, \%

\begin{tabular}{|c|c|c|c|c|c|c|}
\hline \multirow{3}{*}{ Субъекты РФ } & \multirow{3}{*}{$\begin{array}{c}\text { 2013/2014 } \\
\begin{array}{c}\text { Общий } \\
\text { рейтинг }\end{array}\end{array}$} & \multirow{3}{*}{\begin{tabular}{|c|}
$2014 / 2015$ \\
$\begin{array}{c}\text { Общий } \\
\text { рейтинг }\end{array}$
\end{tabular}} & \multicolumn{4}{|c|}{$2015 / 2016$} \\
\hline & & & \multirow{2}{*}{$\begin{array}{l}\text { Общий } \\
\text { рейтинг }\end{array}$} & \multicolumn{3}{|c|}{ В том числе*: } \\
\hline & & & & $\mathbf{P \Pi}$ & НПО & ИС \\
\hline Республика Карелия & 37,4 & 26,6 & 13,8 & 0,0 & 4,5 & 9,3 \\
\hline Республика Коми & 46,2 & 45,4 & 26,0 & 4,1 & 6 & 15,9 \\
\hline Республика Саха (Якутия) & 15,8 & 44,6 & 39,6 & 16,5 & 6,3 & 16,8 \\
\hline Республика Тыва & 31,6 & 31,2 & 10,3 & 2,5 & 1,5 & 6,3 \\
\hline Камчатский край & 24,1 & 29,1 & 19,4 & 0,8 & 4,5 & 14,1 \\
\hline Архангельская область & 34,4 & 31,2 & 26,7 & 14,7 & 0 & 12 \\
\hline Магаданская область & 27,6 & 17,2 & 6,0 & 0,0 & 0 & 6 \\
\hline Мурманская область & 32,9 & 36,7 & 24,4 & 4,0 & 6,9 & 13,5 \\
\hline Сахалинская область & 35,7 & 40,8 & 21,1 & 3,4 & 3,6 & 14,1 \\
\hline Ненецкий АО & 22,0 & 23,6 & 8,0 & 0,50 & 1,5 & 6 \\
\hline Чукотский АО & 6,0 & 10,6 & 1,8 & 0,0 & 0 & 1,8 \\
\hline Ханты-Мансийский АО & 51,0 & 46,2 & 30,6 & 16,2 & 1,8 & 12,6 \\
\hline Ямало-Ненецкий АО & 23,8 & 46,2 & 31,6 & 13,6 & 3,3 & 14,7 \\
\hline Справочно: в среднем по РФ & 35,0 & 35,9 & 24,4 & $\ldots$ & $\ldots$ & $\ldots$ \\
\hline
\end{tabular}

*РП - реализация проектов, НПО - нормативно-правовое обеспечение, ИС институциональная среда.

Источник: составлено и рассчитано авторами на основе данных Единой информационной системы государственно-частного партнерства в Российской Федерации [13].

В 2015/2016 гг. только в 6 из 13 рассматриваемых регионов общий рейтинг превышал или равнялся среднероссийскому, а именно в республиках Коми и Саха, Архангельской и Мурманской областях, Ханты-Мансийском и Ямало-Ненецком автономных округах. Перечисленные регионы характеризуются более высоким уровнем развития институциональной среды и имеют больший опыт реализации проектов по сравнению с другими северными регионами.

Чукотский АО является северным регионом с минимальным рейтингом в течение всего анализируемого периода. Низкое значение общего рейтинга $(1,8 \%)$ в 2015/2016 гг. связано с отсутствием опыта реализации проектов ГЧП, неразвитостью нормативно-правового обеспечения, а также очень низким показателем институциональной 
среды. Опыт реализации проектов ГЧП отсутствует также в Республике Карелия и Магаданской области, которые тоже не отличаются высоким рейтингом в течение всего исследуемого периода.

В случае дальневосточных регионов проблемы привлечения средств в проекты ГЧП связаны не только со сложностью реализации и недостаточной рентабельностью проектов, но и вызваны спецификой регионов как таковой - к примеру, низким платежеспособным спросом, малочисленным населением, чрезмерной протяженностью регионов, сильной удаленностью от Москвы [6].

Наиболее весомым фактором рейтинга является опыт реализации проектов, поскольку каждый последующий ГЧП-проект повышает управленческие компетенции и позитивно влияет на развитие механизмов ГЧП в регионе. Рассмотрим его более подробно. Для этого воспользуемся данными официального ресурса - Единой информационной системы ГЧП в РФ [2]. При анализе учитывались только те проекты, в которых объем частных инвестиций на стадии создания объекта составлял более 1 млн руб. Всего в северных регионах в настоящее время реализуется 86 удовлетворяющих этому условию проектов с суммарным объемом частных инвестиций более 162 млрд руб. (табл. 3). При этом в Магаданской области, Республике Карелия и Чукотском АО подобных проектов ГЧП в настоящее время нет.

В разрезе северных регионов большинство ГЧП-проектов имеют муниципальный статус (46 проектов), также присутствуют региональные проекты (16 проектов) и муниципальные с региональным участием (24 проекта). Основными отраслевыми направлениями являются транспортные, инфраструктурные проекты, проекты в коммунальной и энергетической сферах, социальные проекты. То есть ГЧП востребовано в сферах, необходимых для нормального функционирования социально-экономической системы. Одной из таких сфер является энергетика. В работе [4] показано, что в случае противоречия рыночных принципов и социальной роли энергообеспечения приоритет в государственном регулировании электроэнергетики надо отдавать последнему. Но применение ГЧП может позволить в рамках необходимого государственного регулирова- 
ния обеспечить интересы частных инвесторов в энергообъекты без ущемления интересов населения и социально значимых потребителей энергии. Тем более что частные инвесторы проявляют интерес к этой сфере: так, в Камчатском крае реализуется 8 муниципальных ГЧП-проектов в энергетической сфере.

Таблица 3.

Характеристики проектов ГЧП в северных регионах, объем частных инвестиций которых на стадии создания объекта превышает 1 млн руб.

\begin{tabular}{|c|c|c|c|}
\hline Субъекты РФ & \begin{tabular}{|l|} 
Количество и уровень \\
реализации проектов
\end{tabular} & $\begin{array}{c}\text { Сферы } \\
\text { проектов }\end{array}$ & $\begin{array}{l}\text { Объем инвести- } \\
\text { ций (млн руб.) }\end{array}$ \\
\hline Республика Коми & 2 региональных & $\begin{array}{c}\text { транспортная } \\
\text { социальная }\end{array}$ & 4850 \\
\hline $\begin{array}{l}\text { Республика Саха } \\
\text { (Якутия) }\end{array}$ & $\begin{array}{c}1 \text { муниципальный } \\
21 \text { муниципальный } \\
\text { с региональным } \\
\text { участием } \\
7 \text { региональных }\end{array}$ & $\begin{array}{c}\text { энергетическая } \\
\text { коммунальная } \\
\text { социальная }\end{array}$ & $13565^{*}$ \\
\hline Республика Тыва & 2 региональных & социальная & 200 \\
\hline Камчатский край & 8 муниципальных & энергетическая & 4343 \\
\hline Архангельская область & 21 муниципальный & коммунальная & $795 *$ \\
\hline Мурманская область & 1 региональный & коммунальная & 1250 \\
\hline Сахалинская область & $\begin{array}{l}3 \text { муниципальных с ре- } \\
\text { гиональным участием }\end{array}$ & \begin{tabular}{|r|} 
энергетическая \\
коммунальная
\end{tabular} & 2285 \\
\hline Ненецкий АО & 1 муниципальный & коммунальная & 13 \\
\hline Ханты-Мансийский АО & $\begin{array}{c}10 \text { муниципальных } \\
1 \text { региональный }\end{array}$ & $\begin{array}{c}\text { энергетическая } \\
\text { коммунальная } \\
\text { социальная }\end{array}$ & 14986 \\
\hline Ямало-Ненецкий АО & $\begin{array}{c}5 \text { муниципальных } \\
3 \text { региональных }\end{array}$ & $\begin{array}{c}\text { энергетическая } \\
\text { транспортная } \\
\text { коммунальная } \\
\text { социальная } \\
\end{array}$ & 120214 \\
\hline $\begin{array}{l}\text { Всего по северным } \\
\text { регионам }\end{array}$ & 86 & 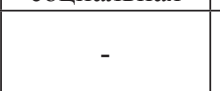 & 162501 \\
\hline
\end{tabular}

*Нет данных об объеме инвестиций: в Республике Саха - по одному проекту, в Архангельской области - по 3 проектам.

Источник: составлено авторами на основе данных Единой информационной системы государственно-частного партнерства в Российской Федерации [2]. 
Наиболее активным регионом по количеству ГЧП-проектов является Республика Саха (Якутия). В ней наибольшую долю занимают проекты в социальной сфере: выполняется комплексная реализация 21 проекта по детским садам. Общий размер частных инвестиций в Республике составил 13,565 млрд руб.

По объему частных инвестиций выделяется Ямало-Ненецкий $\mathrm{AO}$, в котором более 120 млрд руб. частного инвестирования приходится всего на 8 проектов. Причина этого - реализация крупного проекта по созданию и эксплуатации железнодорожной линии необщего пользования «Бованенково-Сабетта» (объем инвестиций в этот проект - более 113 млрд рублей) [2].

Таким образом, в ряде северных регионов механизм ГЧП активно применяется, что оказывает положительный эффект на их социально-экономическое развитие. Тем не менее, в некоторых регионах (Магаданская область, Республика Карелия, Ненецкий АО, Чукотский АО, Республика Тыва) этот механизм используется недостаточно.

\section{Заключение}

В современных условиях государственно-частное партнерство является действенным механизмом согласования интересов бизнеса и государства, позволяющим учитывать интересы общества как конечного потребителя товаров и услуг. Несмотря на то, что дальнейшее развитие ГЧП в России тормозится общим замедлением роста экономики и снижением заинтересованности бизнеса в долгосрочных проектах, исходя из данных исследования, можно говорить о перспективах развития данной формы взаимоотношений государства и бизнеса. Для этого необходимо совершенствовать нормативно-правовое обеспечение ГЧП на основе опыта реализации конкретных проектов, формировать системный подход к ГЧП в регионах, расширять инструменты финансирования проектов ГЧП (например, предоставлять инвесторам гарантии возврата средств), формировать инвестиционно привлекательные условия в целом. Положительную роль сыграет развитие единой системы контроля 
и мониторинга проектов ГЧП на уровне субъектов Федерации, в рамках которой будет отслеживаться весь ход выполнения проектов от подписания соглашения до завершения работ. Необходимо развивать взаимодействие региональной власти и представителей бизнеса, осуществлять информирование бизнеса о потенциальных проектах, которые могут быть реализованы на условиях ГЧП. Это возможно посредством создания специализированного информационного ресурса в сети Интернет или раздела на официальном сайте региона. Уровень доступности информации о проектах ГЧП возможно повысить путем создания площадок для открытой дискуссии представителей власти, бизнеса и населения (общественные слушания) с целью выявить возможные проблемы и найти компромисс на стадии обсуждения проектов.

В северных регионах противоречие интересов бизнеса и государства ощущается острее, чем в умеренных широтах. Затраты на жизнеобеспечение населения и ведение хозяйственной деятельности здесь объективно выше, при этом северные регионы характеризуются недостаточным уровнем развития социальной, транспортной, энергетической инфраструктуры. В подобных условиях, с одной стороны, возникает необходимость направления инвестиций на реализацию социально значимых и инфраструктурных проектов, но с другой стороны, возникают сложности с привлечением к участию в подобных проектах частного бизнеса ввиду их недостаточной рентабельности. Государственно-частное партнерство становится механизмом, который позволяет сгладить эти противоречия. Хотя управляющие компании холдингов часто не заинтересованы в осуществлении вложений в развитие регионов присутствия, однако они нуждаются в доступе к энергии, транспортным путям, а также заинтересованы в социальном благополучии своих работников и членов их семей, поскольку это напрямую влияет на качество рабочей силы.

Таким образом, ГЧП в северных регионах выходит на первое место среди механизмов осуществления стратегий социально-экономического развития регионов. Приведенные выводы подтверж- 
даются практикой ряда северных регионов, в которых в настоящее время уже реализуются проекты в различных отраслях с активным привлечением частных инвестиций, проводится работа по актуализации нормативно-правовой базы ГЧП. При этом нельзя не отметить, что в некоторых регионах этот механизм используется недостаточно. Тем не менее, специфика хозяйственной деятельности в северных регионах, необходимость сглаживания особенно острых противоречий государства и бизнеса, а также формирование нормативно-правовой базы ГЧП на федеральном и региональном уровнях позволяют ожидать, что в ближайшие годы данный механизм взаимодействия государства и бизнеса будет находить в северных регионах более широкое применение.

\section{Сиисок литературы}

1. Амунц Д.М. Государственно-частное партнерство // Справочник руководителя учреждений культуры. 2005. №12. С. 16-24.

2. База проектов. URL: http://www.pppi.ru/projects (дата обращения: 15.12.2016).

3. Варнавский В.Г. Государственно-частное партнерство: некоторые вопросы теории и практики // Мировая экономика и международные отношения. 2011. № 9. С. 41-50.

4. Гасникова А.А. В поисках эффективных мер, направленных на развитие электроэнергетики европейского Севера // Север и рынок: формирование экономического порядка. 2013. № 3. С. 16-20.

5. ГЧП в ручном режиме. На Дальнем Востоке проекты ГЧП прицеливаются на проекты развития инфраструктуры. URL: http://www. eastrussia.ru/material/gchp-v-ruchnom-rezhime (дата обращения: 20.12.2016).

6. Государственно-частное партнерство: теоретические основы, базовые принципы и практика реализации / Под ред. В.В. Глухова. СПб.: Изд-во Политехн. ун-та, 2014. 572 с.

7. Захаров С.В. Социально-экономическое развитие территории на основе государственно-частного партнерства. Часть $1 / /$ Наука Красноярья. 2017. Том 6. № 1. DOI: 10.12731/2070-7568-2017-1-79-102 
8. Крекотнев Р.Н. Государственно-частное партнерство: экономическая природа и принципы применения // Проблемы экономики и управления нефтегазовым комплексом. 2015. № 1. С. 21-27.

9. Курбанов А.Х., Плотников В.А. Государственно-частное партнерство и аутсорсинг: сравнительный анализ структуры и характера отношений // В мире научных открытий. 2013. № 4. С. 33-47.

10. Матаев Т.М. Определение и классификация форм государственночастного партнерства // Российское предпринимательство. 2014. № 7. C. 51-58.

11. Питанов В.А. Государственно-частное партнерство в регионах России: экономическое содержание // Вестник Оренбургского Государственного Университета. 2014. № 4. С. 109-111.

12.Региональная экономика и вопросы североведения / Под ред. В.С. Селина, Т.П. Скуфьиной. Апатиты: Изд-во КНЦ РАН, 2013. $200 \mathrm{c}$.

13.Рейтинг регионов. URL: http://www.pppi.ru/regions (дата обращения: 15.12.2016).

14. Стратегическое позиционирование арктического региона как объекта территориального развития (на примере Хатангско-Анабарского региона) / Шишацкий Н.Г., Брюханова Е.А., Ефимов В.С., Матвеев А.М. // Арктика и Север. 2016. № 25. С. 173-195.

15. Федеральный закон от 13.07.2015 г. № 224-Ф3 «О государственночастном партнерстве, муниципально-частном партнерстве в Российской Федерации и внесении изменений в отдельные законодательные акты Российской Федерации» // Российская газета. 2015. 17 июля. № 156.

16. Чапаргина А.Н. Влияние инвестиционной подсистемы на социально-экономическое развитие региона // Экономические и социальные перемены: факты, тенденции, прогноз. 2012. № 1. С. 147-155.

17. Closing the Infrastructure Gap: The Role of Public-Private Partnerships. A Deloitte Research Study. 2006. 40 p.

18. Infrastructure PPP in emerging markets and developing economies 1991-2015 // June 2016. 40 p. URL: https://ppiaf.org/documents/3551/ download (дата обращения: 19.04.2017). 
19. Green Paper On Public-Private Partnerships And Community Law On Public Contracts and Concessions. URL: http://www.ebrd. com/ downloads/legal/concessions/green.pdf (дата обращения: 25.01.2017).

20.PPP Reference Guide. URL: http://pppknowledgelab.org/guide/sections/1-introduction (дата обращения: 19.04.2017).

21.Public-Private Partnership Handbook. URL: http://www.adb.org/ sites/default/files/institutional-document/31484/public-private-partnership.pdf (дата обращения: 19.04.2017).

\section{References}

1. Amunts D.M. Gosudarstvenno-chastnoe partnerstvo [Public-Private Partnership]. Spravochnik rukovoditelya uchrezhdenii kul'tury, 2005, no. 12, pp. 16-24.

2. Baza proektov [Project base]. http://www.pppi.ru/projects (accessed December 15, 2016).

3. Varnavskii V.G. Gosudarstvenno-chastnoe partnerstvo: nekotorye voprosy teorii i praktiki [Public-Private Partnership: Some Issues of Theory and Practice]. Mirovaya ekonomika i mezhdunarodnye otnosheniya [World Economy and International Relations], 2011, no. 9, pp. 41-50.

4. Gasnikova A.A. V poiskakh effektivnykh mer, napravlennykh na razvitie elektroenergetiki evropeiskogo Severa [In search for effective measures to develop power industry in the European North]. Sever i rynok: formirovanie ekonomicheskogo poryadka [The North and the Market: Forming the Economic Order], 2013, no. 3, pp. 16-20.

5. Glukhov V.V. (ed). Gosudarstvenno-chastnoe partnerstvo: teoreticheskie osnovy, bazovye printsipy i praktika realizatsii [Public-private partnerships: theoretical foundations, basic principles and practice of implementing]. Saint-Petersburg: Izd-vo Politekhn. un-ta, 2014. 572 p.

6. GChP v ruchnom rezhime. Na Dal'nem Vostoke proekty GChP pritselivayutsya na proekty razvitiya infrastruktury [PPP in manual mode. PPP projects are aiming at infrastructure development projects in the Far 
East]. http://www.eastrussia.ru/material/gchp-v-ruchnom-rezhime (accessed December 20, 2016).

7. Zakharov S.V. Sotsial'no-ekonomicheskoe razvitie territorii na osnove gosudarstvenno-chastnogo partnerstva. Chast' 1 [Socio-economic development area based on public-private partnerships. Part 1]. Nauka Krasnoyar'ya [Krasnoyarsk science], 2017. Vol. 6. no. 1. DOI: 10.12731/2070-7568-2017-1-79-102

8. Krekotnev R.N. Gosudarstvenno-chastnoe partnerstvo: ekonomicheskaya priroda i printsipy primeneniya [Public Private Partnership: Economic Nature and Principles of Implementation]. Problemy ekonomiki i upravleniya neftegazovym kompleksom, 2015, no. 1, pp. 21-27.

9. Kurbanov A.Kh., Plotnikov V.A. Gosudarstvenno-chastnoe partnerstvo i autsorsing: sravnitel'nyy analiz struktury i kharaktera otnosheniy [Public-Private Partnerships and Outsourcing: a Comparative Analysis of the Structure and Nature of the Relationship]. V mire nauchnykh otkrytiy, 2013, no. 4, pp. 33-47.

10. Mataev T.M. Opredelenie i klassifikatsiya form gosudarstvenno-chastnogo partnerstva [Definition and classification of the public private partnership forms]. Rossiiskoe predprinimatel'stvo [Russian Journal of Entrepreneurship], 2014, no. 7, pp. 51-58.

11. Pitanov V.A. Gosudarstvenno-chastnoe partnerstvo v regionakh Rossii: ekonomicheskoe soderzhanie [Public-private partnership in the regions of Russia: the economic content]. Vestnik Orenburgskogo Gosudarstvennogo Universiteta [Vestnik of the Orenburg State University], 2014, no. 4, pp. 109-111.

12. Selin V.S., Skuf'ina T.P. (eds). Regional'naya ekonomika i voprosy severovedeniya [Regional economy and issues of northern studies]. Apatity: Izd-vo KNTs RAN, 2013. 200 p.

13. Reyting regionov [Rating of the regions]. http://www.pppi.ru/regions (accessed December 15, 2016).

14. Shishatskii N.G., Bryukhanova E.A., Efimov V.S., Matveev A.M. Strategicheskoe pozitsionirovanie arkticheskogo regiona kak ob'ekta territorial'nogo razvitiya (na primere Khatangsko-Anabarskogo regiona) [Strategic positioning of the Arctic region as an object of territorial de- 
velopment (on the example of the Hatangsko-Anabarsky region)]. Arktika i Sever [Arctic and North], 2016, no. 25, pp. 173-195.

15.Federal'nyy zakon ot 13.07.2015 N 224-FZ «O gosudarstvenno-chastnom partnerstve, munitsipal'no-chastnom partnerstve v Rossiyskoy Federatsii i vnesenii izmeneniy v otdel'nye zakonodatel'nye akty Rossiyskoy Federatsii» [The Federal Law of 13.07.2015 \#224-FZ “About Public-private partnership, Municipal-private Partnership in the Russian Federation and the Introduction of Amendments to Certain Legislative Acts of the Russian Federation"]. Rossiyskaya gazeta. 2015. July 17. No 156.

16. Chapargina A.N. Vliyanie investitsionnoi podsistemy na sotsial'no-ekonomicheskoe razvitie regiona [Influence of investment subsystem on the region's socio-economic development]. Ekonomicheskie i sotsial'nye peremeny: fakty, tendentsii, prognoz [Economic and social changes: facts, trends, forecast], 2012, no. 1, pp. 147-155.

17. Closing the Infrastructure Gap: The Role of Public-Private Partnerships. A Deloitte Research Study. 2006. 40 p.

18. Infrastructure PPP in emerging markets and developing economies 1991-2015. June 2016. 40 p. https://ppiaf.org/documents/3551/download (accessed April 19, 2017).

19. Green Paper On Public-Private Partnerships And Community Law On Public Contracts and Concessions. http://www.ebrd.com/downloads/ legal/concessions/green.pdf (accessed January 1, 2017).

20.PPP Reference Guide. http://pppknowledgelab.org/guide/sections/1-introduction (accessed April 19, 2017).

21.Public-Private Partnership Handbook. http://www.adb.org/sites/default/files/institutional-document/31484/public-private-partnership.pdf (accessed April 19, 2017).

\section{ДАННЫЕ ОБ АВТОРАХ}

Гасникова Анастасия Александровна, старший научный сотрудник, кандидат экономических наук

Институт экономических проблем им. Г.П. Лузина Кольского научного ичентра РАН 
ул. Ферсмана, 24a, г. Апатиты, Мурманская обл., 184209, Российская Федераиия

agasnikova@iep.kolasc.net.ru

Чапаргина Анастасия Николаевна, старший научный сотрудник, кандидат экономических наук

Институт экономических проблем им. Г.П. Лузина Кольского научного изентра РАН, ул. Ферсмана, 24а, г. Апатиты, Мурманская обл., 184209, Российская Федерации achapargina@yandex.ru

\section{DATA ABOUT THE AUTHORS}

Gasnikova Anastasia Aleksandrovna, Senior Researcher, Candidate of Economic Sciences

Luzin Institute for Economic Studies of Kola Science Centre of $R A S$

24a, Fersman Str., Apatity, 184209, Russian Federation agasnikova@iep.kolasc.net.ru

SPIN-code: 5002-6996

Chapargina Anastasia Nikolaevna, Senior Researcher, Candidate of Economic Sciences

Luzin Institute for Economic Studies of Kola Science Centre of RAS

24a, Fersman Str., Apatity, 184209, Russian Federation achapargina@yandex.ru SPIN-code: 9362-0741 